\title{
Scanning electron microscope study of the development of the human respiratory acinus
}

\author{
SUSAN A DILLY \\ From the Department of Histopathology, St George's Hospital Medical School, London
}

ABSTRACT Plastic corrosion casts were made of lungs from fetuses aged from 19 weeks' gestation to term and of lungs from a child and two adults to study the development of the respiratory acinus. To achieve reliable infusion of the most peripheral airspaces a high viscosity plastic was used that is not known to have been employed previously for corrosion casting of lungs. The casts were examined in the scanning electron microscope and showed the increase both in number and in length of the. airways distal to the terminal bronchiole and also the change in shape and complexity of the most peripheral airspaces as the lung matures. The terminal airspaces change from short, simple, tubular endings at 19 weeks' gestation to short, shallow saccules from around 30 weeks' gestation to full term and contrast with the deep cup shaped alveoli in the adult. Measurements of the size of the terminal airspace at various stages of development are presented. This new approach, allowing three dimensional study of the peripheral airspaces of the developing lung, will be useful for investigating the lung pathology of neonates.

In the development of the human lung the preacinar airway branching is complete by 16 weeks' gestation $^{1}$ and in subsequent development changes occur within the acinus, the collection of airways supplied by a terminal bronchiole. These changes have been summarised by Hislop and Reid ${ }^{2}$ (fig 1). They and Boyden ${ }^{3}$ documented the number of generations of airways during development and the change in appearance of the most peripheral airspaces from small numbers of shallow airspaces at 19 weeks' gestation to more complex clusters of airsacs and shallow primitive alveoli in the newborn and finally to the deep, cup shaped alveoli of the adult. These observations were based on models of lungs produced by the Born waxplate reconstruction method at various ages from 30 weeks' gestation to 6 years 8 months, ${ }^{3-7}$ with additional information from serial and step sections of lungs from adults, children, and fetuses. ${ }^{28-12}$

An alternative approach for studying the peripheral airspaces was used by Boyden and Tompsett, ${ }^{7}$ who produced the first resin cast to show the terminal airspaces of an infant lung in a premature infant of 29 weeks' gestation. The injection medium

Address for reprint requests: Dr SA Dilly, Department of Histopathology, Royal Marsden Hospital, Sutton, Surrey.

Accepted 15 June 1984 penetrated as far as the expanded ends of the transitional ducts and they noted the smooth nature of the airways compared with those of a 10 month old baby, in which the alveolar ducts were studded with alveoli. They comment that they were unable to produce casts to show structures distal to the transitional ducts because penetration of the alveolar walls occurred, resulting in a completely solid lung.

This paper describes how casts were made of the most peripheral airspaces of fetal lungs from 19 weeks' gestation to term and presents scanning electron micrographs to illustrate the changes occurring in the respiratory acinus during fetal development. Lungs from a child and two adults were examined by the same technique and are included for comparison.

\section{Methods}

The specimens chosen for scanning electron microscopic examination were from fetuses of gestational ages of 19 (two specimens), 22, 23, 28, 31, 32 (two specimens), 34, 36, 37 (two specimens), and 38 weeks and from a child of 5 years and adults of 23 and 58 years. The term gestational age is used synonymously with "conceptional age"; it is dated from two weeks after the last recorded menstruation and is supported by clinical, ultrasound, and postmortem assessment of maturation. The fetuses of 
$19,22,23$, and 28 weeks' gestation were obtained from spontaneous abortions. The fetuses of 31,32 (1), 34, 36, and 38 weeks' gestation were stillborn with evidence of acute anoxic damage. The fetuses of 32 (1) and 37 (1) weeks' gestation had both sustained intraventricular haemorrhages and died within six hours of delivery. The other fetus of 37 weeks' gestation died in utero after an antepartum haemorrhage. The child's lung was from a 5 year old with a two year history of acute lymphoblastic leukaemia, which may have retarded growth. The adult lungs were from a man of 23 years dying from septicaemia and from a woman of 58 dying from acute myocardial infarction.

All of the subjects had a full postmortem examination supported by histological examination of the tissues. The fetuses were normal except for their immediate cause of death and the child and adults had no evidence of lung disease.

The fetal lungs were removed from the chest soon after death and inflation fixed with $10 \%$ formol saline via the trachea or main bronchus. The lungs were inflated to about their normal size, the main airway was then tied, and the lungs were kept floating in formol saline. After a variable fixation time (minimum two days, maximum six months) a plastic injection cast was made by infusing Tensol Cement No 70 (ICI). This material has a high viscosity so that it remains within the terminal air sacs and does not diffuse through the air sac walls. It requires a high infusion pressure, however, and this was achieved with a hand held syringe. The infusion was stopped after five to 10 minutes, when the plastic started leaking from a small cut made in the periphery of the lung. Tensol Cement No 70 polymerises over about six to 12 hours, during which it shrinks by less than $6 \%$ (A Boyden, personal communication) and digestion was commenced after 48 hours.

The lung tissues were digested by suspending the injected lung in concentrated potassium hydroxide solution for about six hours followed by 18 hours' continuous washing in tap water. This was repeated until a clear cast was obtained, which took from three to 10 days, depending on the size of the lung. The cast was then washed in several changes of distilled water in an ultrasonicator before air drying. Small pieces of the cast were dissected off, mounted on stubs, and gold coated in a Polaron E5100 sputter coater. They were examined in a Cambridge Stereoscan Type 96113 Mark 2A and Coates and Welter scanning electron microscope at variable accelerating voltages $(15-30 \mathrm{Kv})$.

In most cases one lung was infused with plastic while the other was processed through paraffin wax for examination of haematoxylin and eosin sections.
In most cases inflation fixation was via the trachea so that both the corrosion casted lung and the sectioned lung were inflated to the same extent.

The adult and child lungs were inflation fixed with formol saline through a main bronchus at a continuous pressure of $30 \mathrm{~cm} \mathrm{H}_{2} \mathrm{O}$ for three hours. The main bronchus was then tied and the lung floated in fixative for 48 hours. Infusion with the casting material was designed to resemble the method used for the fetal lungs as closely as possible. Thus airways were dissected until one was reached with an internal diameter of about $5 \mathrm{~mm}$. This was infused with Tensol Cement with a hand held syringe and then processed in the same way as the fetal lungs.

MEASUREMENT OF TERMINAL AIRSPACE SIZE A mean terminal airspace diameter was estimated on each specimen by measuring a minimum of 50 terminal airspaces. In irregularly shaped airspaces the average diameter was used. The measurements were taken directly from the appropriately calibrated scanning electron microscope screen and from photographs.

\section{DEFINITIONS}

The Commission on Embryological Terminology ${ }^{13}$ has suggested the following terms to describe the stages of fetal lung development: embryonic period: first five weeks after ovulation; pseudoglandular period: 5th-17th week of gestation; canalicular period: 13th-25th week of gestation ${ }^{14}$ is or 16 th24 th week of gestation; ${ }^{16}$ terminal sac period: end of canalicular period to term.

The anatomical terms used in this paper are defined as follows (fig 1): terminal bronchiolus: the last airway before a respiratory bronchiolus, which supplies an acinus and is lined by ciliated columnar or cuboidal epithelium interspersed with nonciliated bronchiolar cells; respiratory bronchiolus: in the adult this has alveoli opening into it and has part of the wall lined by ciliated epithelium but during the canalicular period it is lined by flattened epithelium, which becomes a mixture of flattened and cuboidal epithelium during the terminal sac period; transitional duct: airway lined by flattened epithelium, which links the respiratory bronchiolus to the saccules during the terminal sac period-this later becomes an alveolar duct; saccule: this is a large, thin walled air space lined by flattened epithelium present from about 28 weeks' gestation to 2 months after birth-it is then represented by the alveolar duct; alveolar duct: in the adult this has alveoli opening into it and nowhere has cuboidal epithelium (cf respiratory bronchiolus)-before birth it is represented by transitional ducts and saccules; alveolar sac: in the adult this is the final airway 

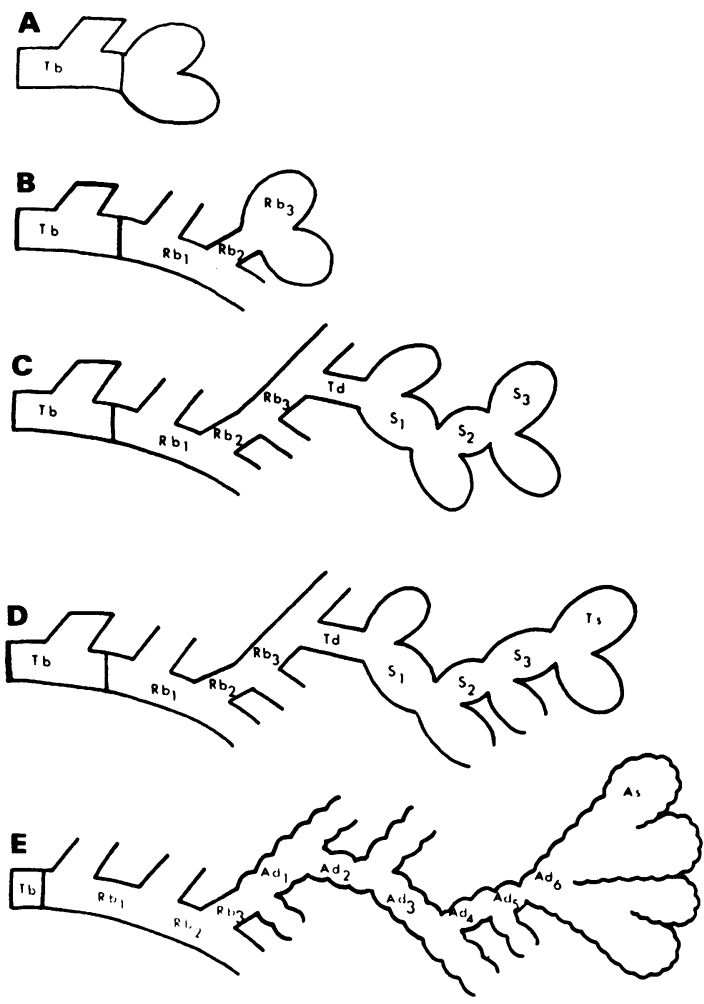

Fig 1 Diagrammatic representation of the acinus at five stages of development. At all ages each generation of airways is drawn the same length, an increase in length representing an increase in the number of generations. $A$ given generation may be traced down the same vertical line so that remodelling in its structure may be followed. Each structure within the acinus is identified by letters and where appropriate a numeral indicating the number of divisions it has undergone. $A-16$ weeks' gestation; $B-19$ weeks' gestation; $C-28$ weeks' gestation; $D-$ birth; $E-7$ years. $\mathrm{Tb}$-terminal bronchiole; $R \mathrm{~b}$-respiratory bronchiole; $T d$-transitional duct; $S$-saccule; $T s$-terminal saccule; Ad-alveolar duct; As-Alveolar sac. Adapted from Hislop and Reid. ${ }^{2}$

and only has alveoli arising from it.

"Airspace" is used as a non-specific term for any part of the peripheral respiratory tree. "Terminal airspace" is the final airspace-that is, saccule from 28 weeks' gestation and alveolus from the first year.

\section{Results}

\section{NINETEEN WEEKS' GESTATION}

The most striking feature at this gestational age is the simplicity of the acinus. The airspaces are clearly visible without dissection because of the high interstitial tissue to airspace ratio at this age (fig 2 ).

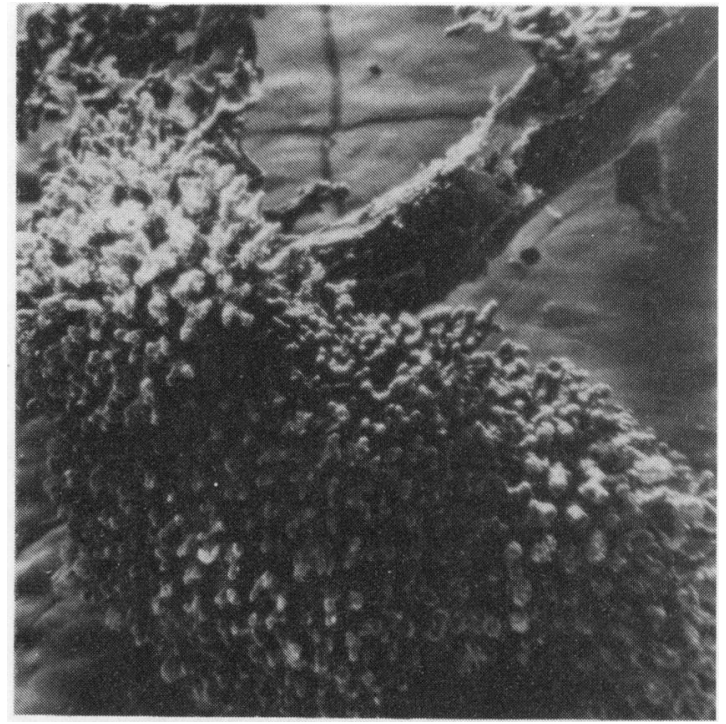

Fig 2 Part of a lobule from the right lower lobe of the lung of a fetus of 19 weeks' gestation showing the simplicity of the terminal branching pattern and the small amount of space occupied by airspaces compared with the interstitial tissue. $(\times 41$.

Although some of the histological features of the wall, which are used to identify the various components of the respiratory tree, are lost by making plastic corrosion casts, cell imprints can provide much information. Figures 3, 4, and 5 show the regular indentations of cuboidal or columnar cells forming an epithelium to line the airways up to about $50 \mu \mathrm{m}$ from the periphery. These airways are probably first order (generation) bronchioles. They most commonly divide dichotomously with the daughter branches almost perpendicular to the parent branch, so forming a letter T (fig 3 ) but they also occasionally branch trichotomously (fig 5). The daughter branches show occasional indentations by cuboidal or columnar cells but these do not form a complete epithelium. These airways are considered to be second order respiratory bronchioles. They usually end in two to five smooth walled, dome shaped airspaces, which lack deep cell impressions but have occasional shallow cell impressions. The shallow cell impressions are important for distinguishing between the true termination of an airspace and artefactual end due to incomplete infusion of plastic, which gives totally smooth regularly spherical surfaces.

The first order respiratory bronchiole is about $40 \mu \mathrm{m}$ wide and the second order bronchiole only slightly narrower ( $30 \mu \mathrm{m}$ wide). The lack of branching of the final airspaces and the presence of only small protrusions rather than true cup shaped alveoli 


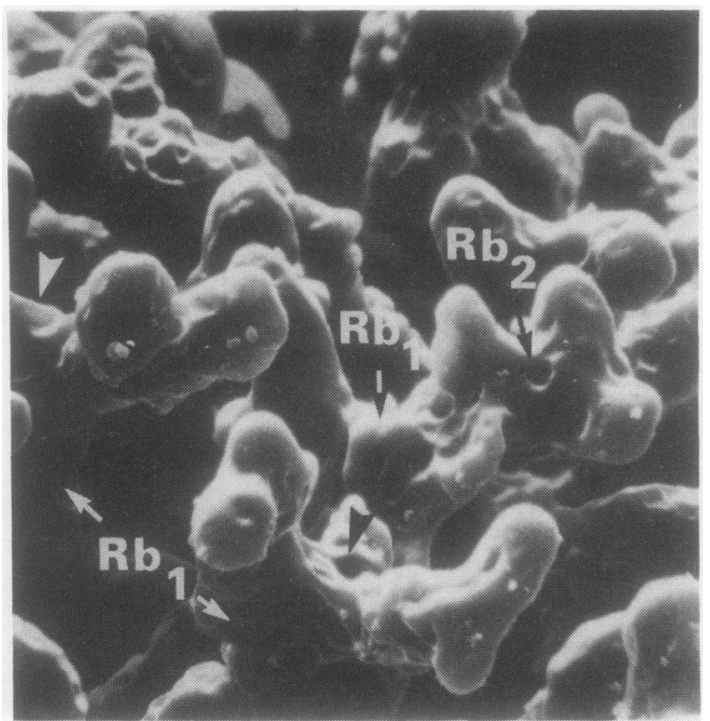

(a)

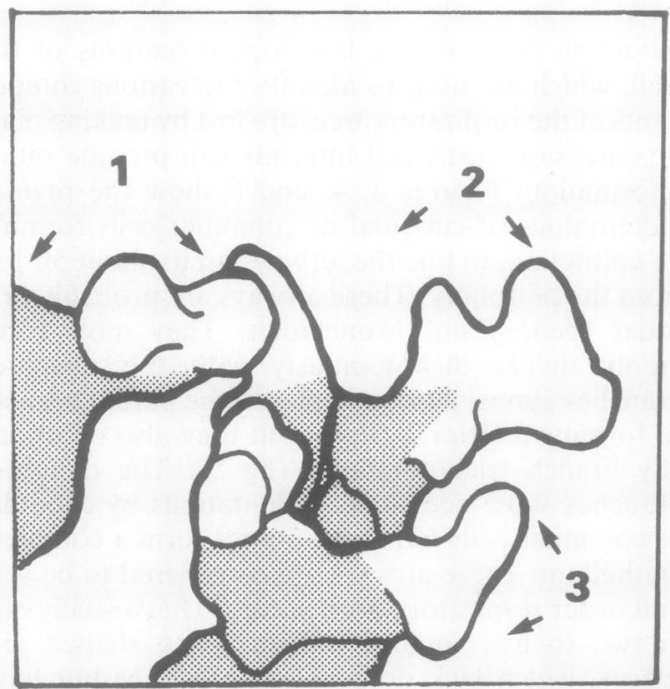

(b)

Fig 3 (a) First order respiratory bronchioles $\left(R b_{1}\right)(19$ weeks' gestation) show the indentations of a columnar or cuboidal epithelium. These are seen branching dichotomously (7) to give second order respiratory bronchioles $\left(R b_{2}\right)$, which bear dome shaped final airspaces. ( $\times$ 414.) (b) Diagram of three groups of terminal airspaces from $(a)$. The stippled area indicates the extent of the complete cuboidal-columnar epithelium. Beyond this there are isolated cuboidal-columnar cell impressions in the area between the mouths of the final airspaces.

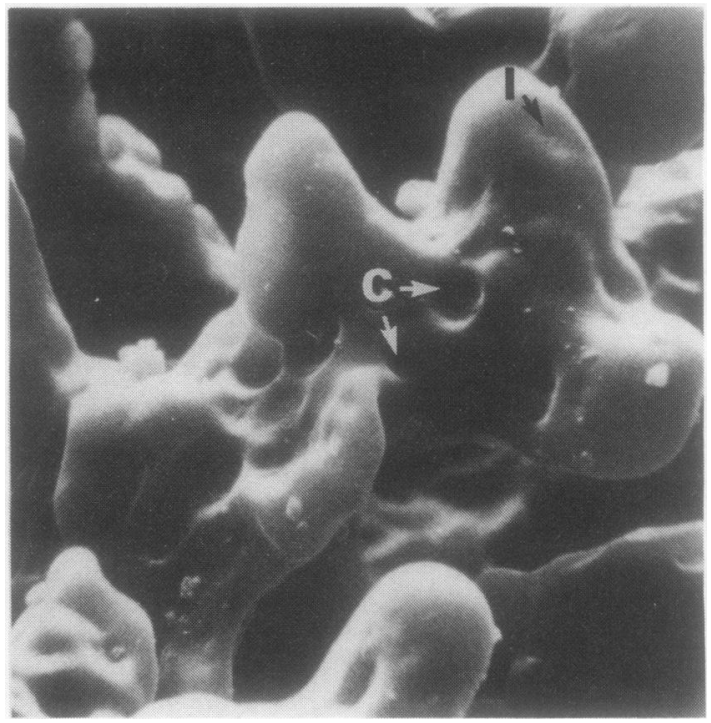

Fig 4 A higher power view of the first order respiratory bronchioles at 19 weeks' gestation shown in fig 3: smooth walled airspaces with shallow cell indentations (I) arising from a wide second order respiratory bronchiole indented by deep cuboidal-columnar $(C)$ cell impressions. $(\times 870$. $)$

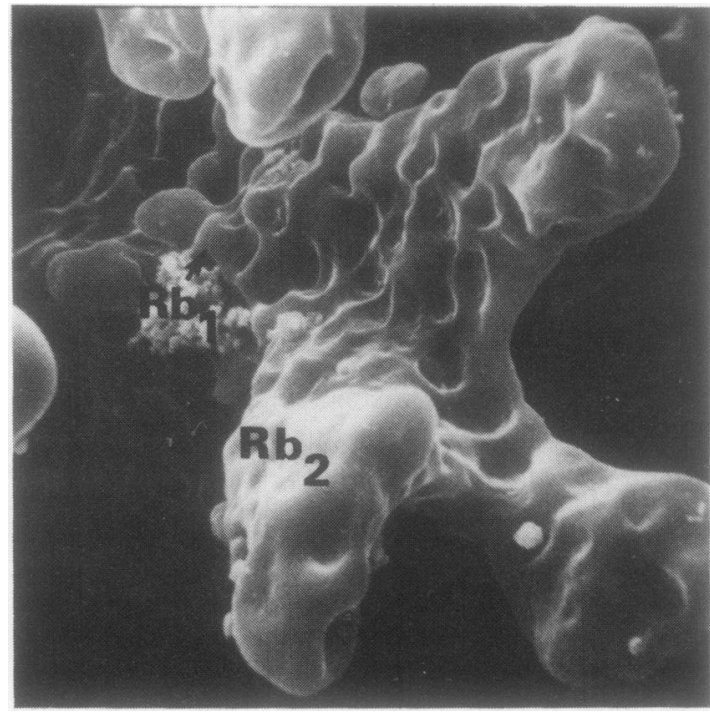

Fig 5 A first order bronchiole ( $\left.R b_{1}\right)$ (19 weeks' gestation) divides trichotomously into second order bronchioles $\left(R b_{2}\right)$, which have blunt expanded ends. $(\times 827$.) 


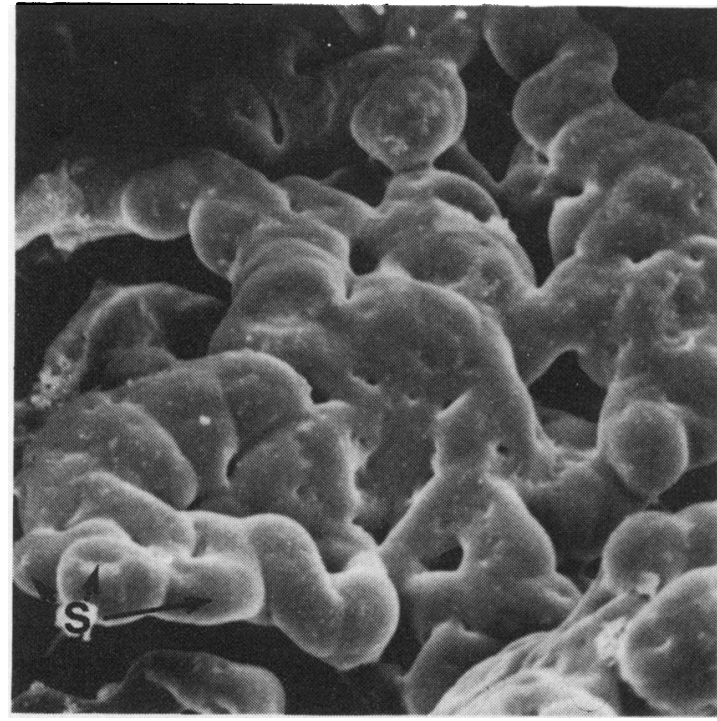

Fig 6 A terminal cluster from the right middle lobe of a 23 weeks' gestation fetus showing an irregular cluster formed of several generations of saccules. (S). Note the shallowness of the final airspaces. $(\times 866$.

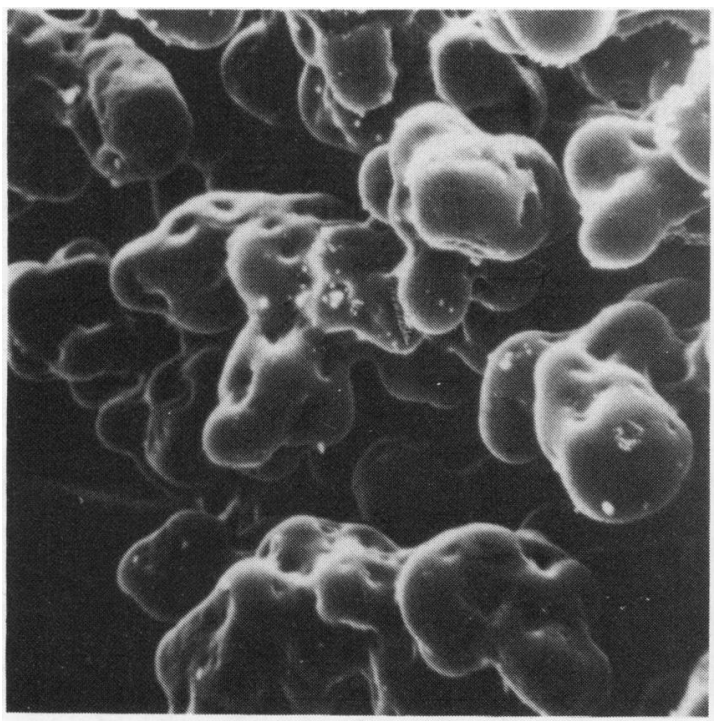

Fig 7 Terminal clusters at 32 weeks' gestation, formed of a collection of deeper, more rounded final airspaces, which are larger and have more generations than during the canalicular period (cf fig 3). ( $\times 153$.)

gives the overall impression of a hawthorn bush rather than the "bunch of grapes" appearance of the adult acinus.

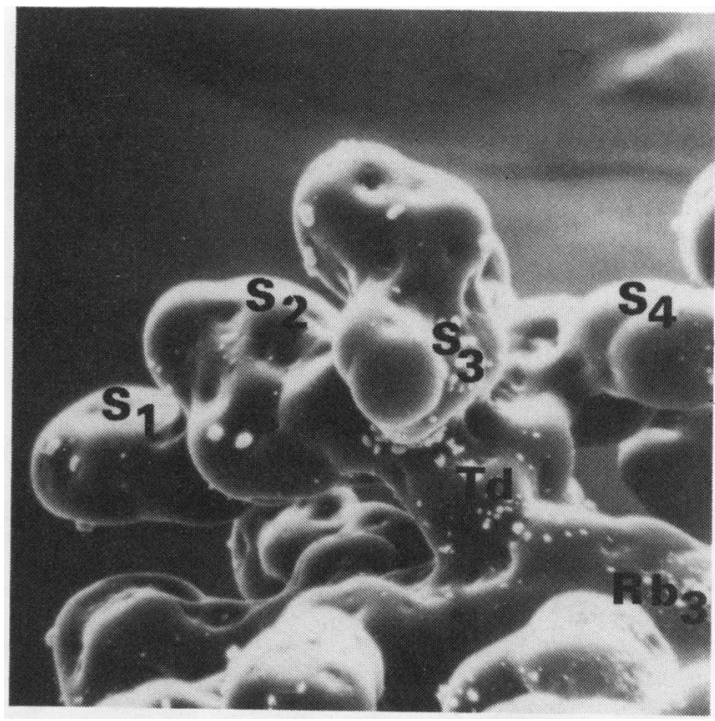

Fig 8 Final order airways at 32 weeks' gestation, probably a third order respiratory bronchiole $\left(R b_{3}\right)$ and short straight transitional duct $(T d)$, leading to a cluster of saccules $\left(S_{1}, S_{v}\right.$ $\left.S_{3}, S_{4}\right)$ (see text for details). (× 174.)

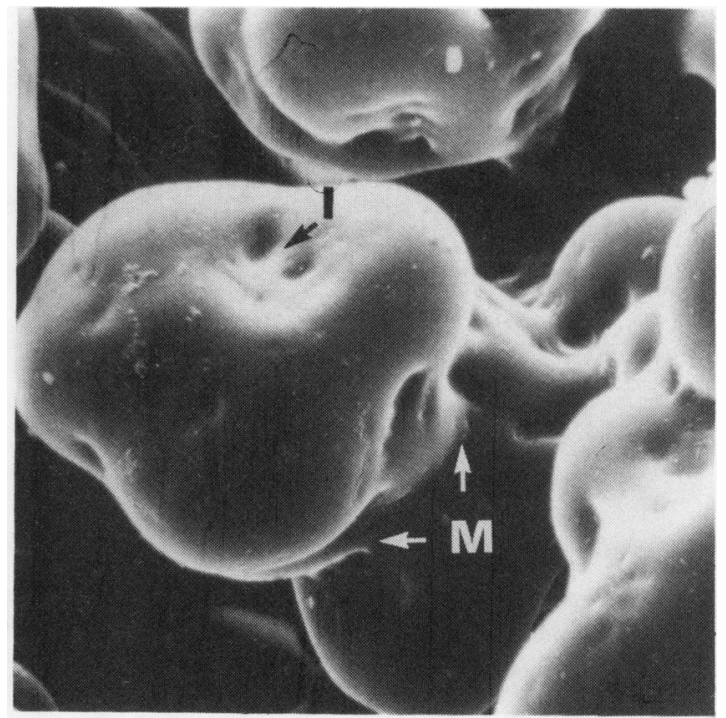

Fig 9 Closer view of a saccule (32 weeks' gestation) showing the slightly constricted mouth (M) of a terminal sac which is approximately spherical in shape but indented by cell impressions $(I) .(\times 435$.

TWENTY TWO AND TWENTY THREE WEEKS' GESTATION

The branching of the cuboidal or columnar epithel- 


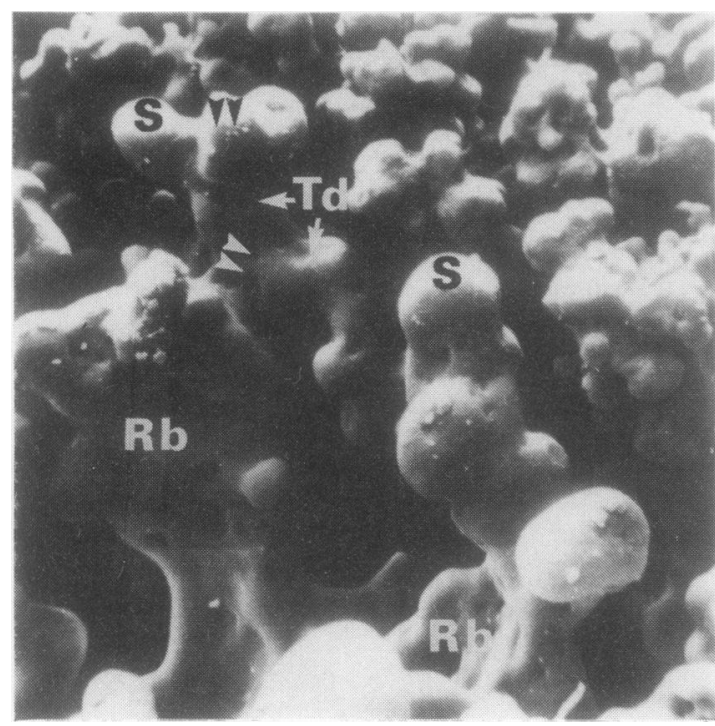

Fig 10 Group of peripheral airspaces from the right middle lobe of a full term infant showing respiratory bronchioles $(R b)$, transitional ducts $(T d)$, and saccules $(S)$. Underfilling of the saccules in one area allows the trichotomous branching $(Y)$ to be seen. $(\times 138$.

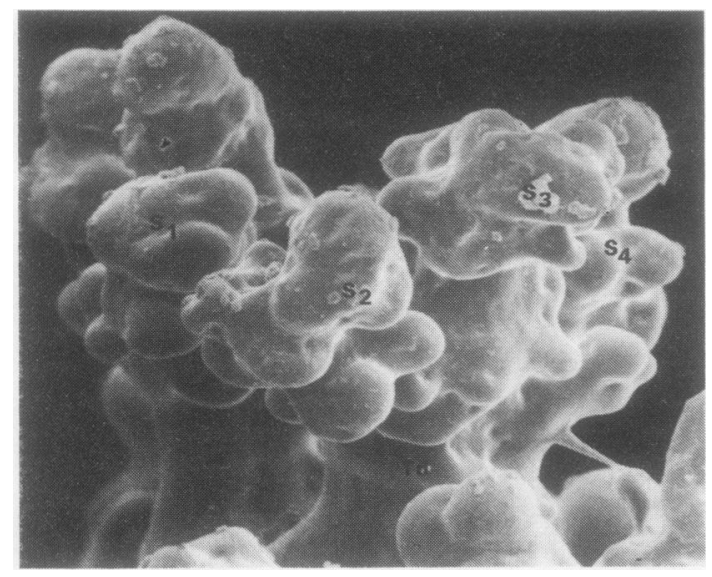

Fig 11 Transitional duct from a full term infant supplying a cluster of saccules $\left(S_{1}, S_{2}, S_{3}, S_{4}\right)$ (see text for comparison with fig 8). $(\times 160$.

ial lined airways is more complex than at 19 weeks' gestation and the number of generations of airways has increased. There is also a new component present in the acinus for the first time-namely, saccules, which are the most peripheral airspaces (fig 6). They are irregular in shape and size and are shallow with wide mouths. The mouths are well demarcated so that the appearance of a group of saccules is similar to that of the shallow alveoli opening into the alveolar duct in the adult lung (see fig 13). The cell impressions in these most peripheral airspaces are those of flattened epithelium.

\section{TWENTY EIGHT TO THIRTY FOUR WEEKS GESTATION}

The terminal clusters composed of several generations of saccules have increased in complexity (fig 7) and are now linked to the final order respiratory bronchiole by a short straight transitional duct (fig 8 ). The terminal clusters vary considerably in size and shape but are formed from about three to 10 individually recognisable saccules (fig 9). It is, however, impossible to count the number of generations of saccules (that is, the number of branching points) distal to the transitional duct as the distance between branching points is very short and the saccules merge together.

\section{TERM (36-38 WEEKS' GESTATION)}

There has been further enlargement and increase in complexity of the final airspace from the lung of 32 weeks' gestation. However, the saccules are still shallow by comparison with those of the adult lung. The branching of the final airways (respiratory bronchiole and transitional duct) is most commonly dichotomous or trichotomous and is sharply angled, running approximately perpendicular to the parent branch (fig 10). Figure 11 shows a group of peripheral airspaces in a full term lung similar to those of 32 weeks' gestation (fig 8). In each there is a short transitional duct leading to a cluster of saccules. The number of individually recognisable groups visible from the front is four in both cases; the number of component parts of each group has, however, increased in the full term lung. This has the effect of greatly increasing the amount of airspace relative to the interstitial space.

At all stages of intrauterine lung development the epithelial cell impressions in the trachea and major and minor bronchi were highly organised so that they formed longitudinal lines that spiralled loosely in the direction of the airflow.

\section{FIVE YEARS}

The terminal airspaces have changed dramatically from the infant lung and closely resemble those of the adult lung with deep cup shaped alveoli arising from alveolar sacs and respiratory bronchioles. The sizes of the airspaces, however, are smaller than in the adult.

\section{ADULT}

The respiratory acinus of the adult lung is a large and very complex structure with major regional variations. ${ }^{17}$ The method used here shows the shapes of 


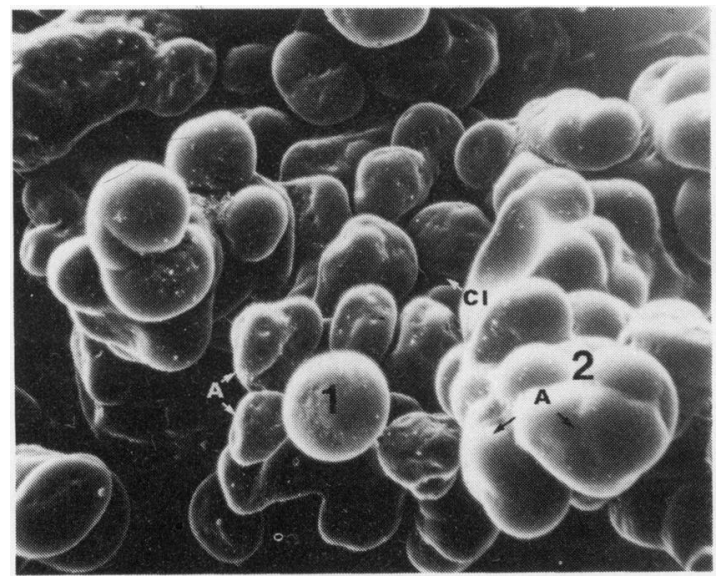

Fig 12 Adult lung with deep, cup shaped aveoli $(A)$ separated by deep clefts $(\mathrm{Cl})$. The shape of the alveoli is largely determined by the space available and the amount the alveoli are inflated. $(\times 30$.)

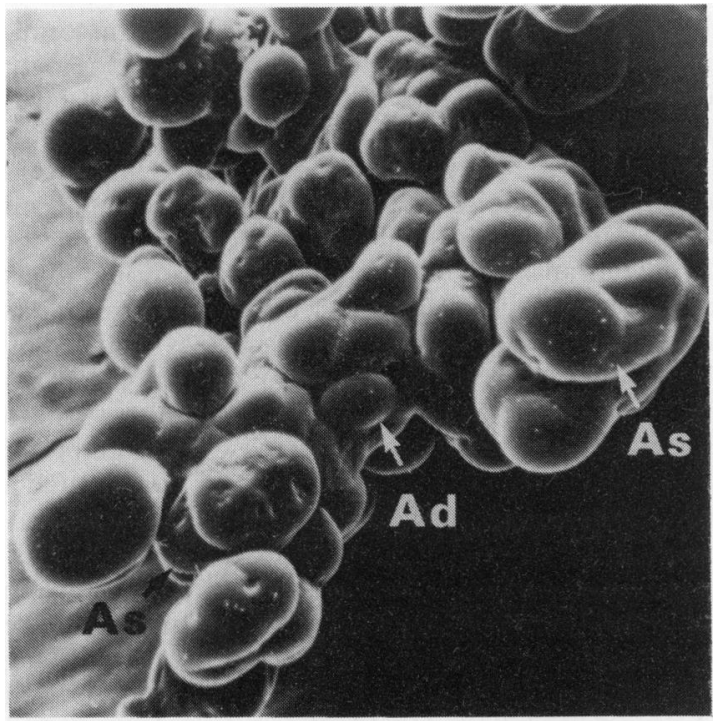

Fig 13 Alveolar duct (Ad) from an adult studded with shallow alveoli with wide mouths and leading into two alveolar sacs (As), from which many alveoli arise. (× 33.)

the terminal airspaces in the adult compared with those in the fetus. The two main differences are the great reduction in interstitial space in the adult, so that the surface is a mass of deep cup shaped alveoli separated by narrow clefts (fig 12) and alveoli opening directly into peripheral airways (alveolar ducts) (fig 13). These alveoli are shallow and wide mouthed compared with the peripheral ones and resemble the shallow final airspaces seen during

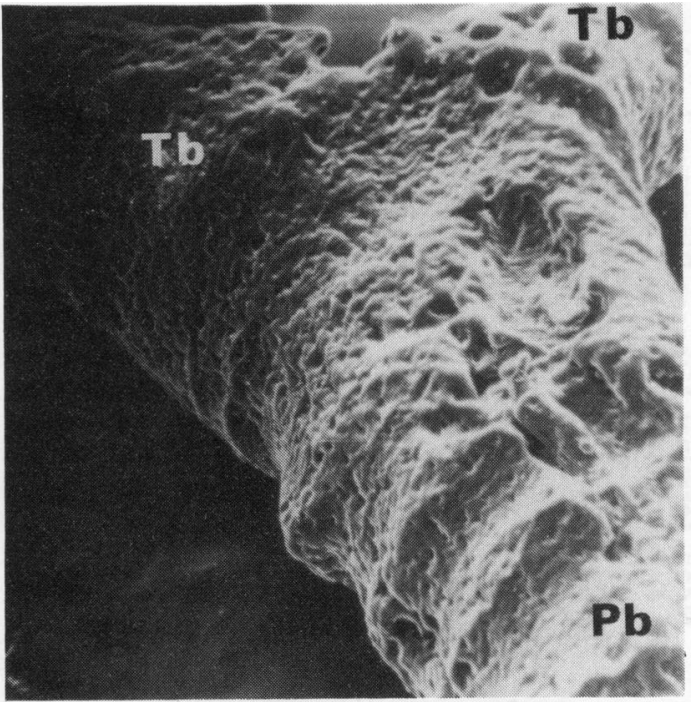

Fig 14 A penultimate bronchiole $(\mathrm{Pb})$ from an adult dividing into two terminal bronchioles (Tb), each of these airways showing the regular cell impressions of cuboidal-columnar epithelium. $(\times 72$.

development. There are no longer any airways visible that are indented by columnar or cuboidal epithelium unless the peripheral airspaces are dissected away (fig 14). The alveoli measure about 200-300 $\mu \mathrm{m}$ in diameter and the alveolar sacs are about $400 \mu \mathrm{m}$ in width and $600 \mu \mathrm{m}$ in length. The alveolar dimensions agree with those of Pump ${ }^{18}$ and Schreider and Raabe ${ }^{17}$ and the alveolar sac dimensions are similar to those of Pump. ${ }^{18}$

\section{CHANGES IN ALVEOLAR OR TERMINAL}

\section{AIRSPACE DIAMETER DURING DEVELOPMENT}

Figure 15 shows the increase in terminal airspace diameter from fetal life through childhood to adult life. Although most of the increase in volume of the respiratory acinus which occurs with age is a result of the increase in number of alveoli, ${ }^{19}$ there is also an increase in the size of the alveoli. From 19 weeks' gestation to term the average diameter ranges from $25 \mu \mathrm{m}$ to $60 \mu \mathrm{m}$. This has more than doubled by the age of 5 years and doubled again by the time body growth is completed.

\section{PULMONARY LYMPHATICS}

In several of the lung casts the lymphatics had been permeated by the plastic. This resulted in a fine lattice over the surface of the lung outlining the positions of the septa. This corresponds to the superficial lymphatic drainage of the lung. In some cases there was also filling of the septal lymphatics leading to 


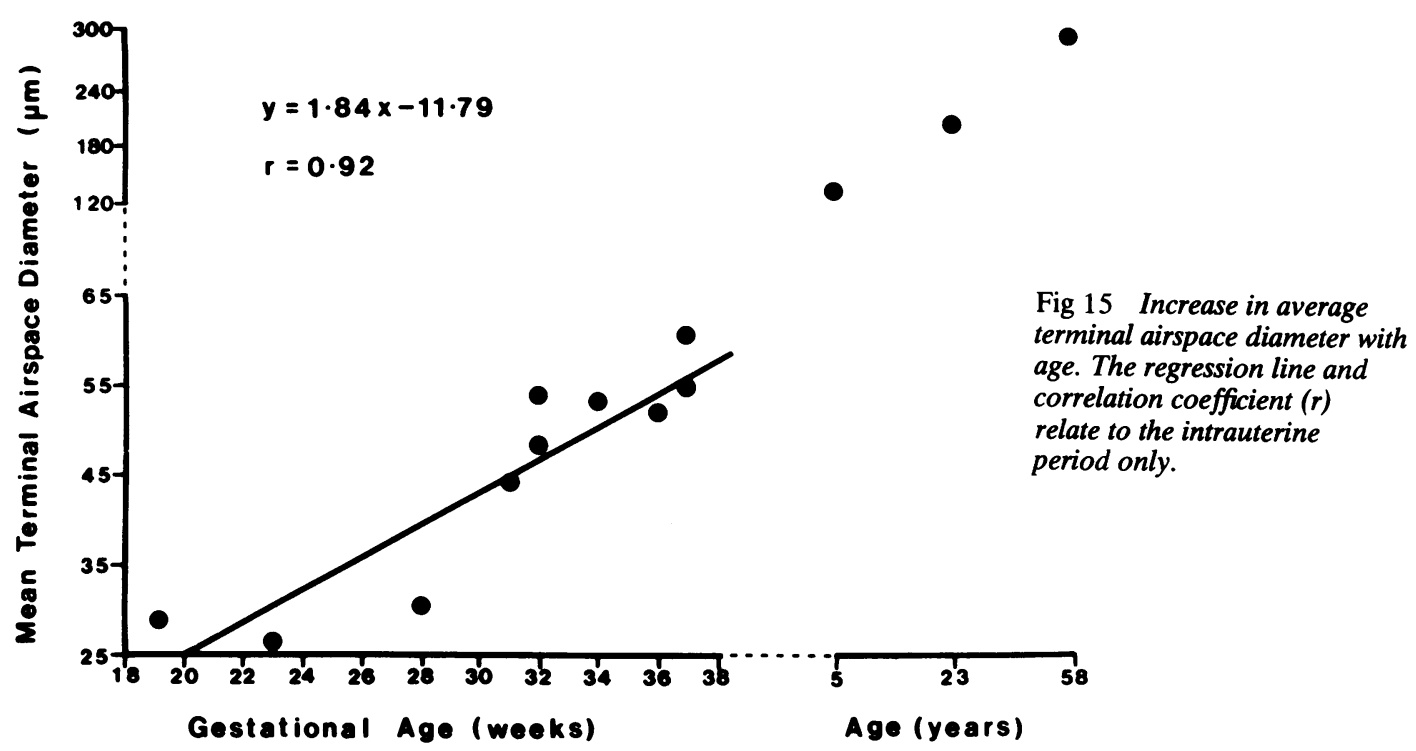

the deep lymphatics, in one case extending right to the hilar lymphatic vessels. In all cases the cast of the more superficial parts of the lymphatic system could easily be dissected from the cast of the airways. The precise points of communication between the airways and lymphatics could not, however, be identified.

\section{Discussion}

This paper has described some of the changes which occur in the peripheral airspaces of the lung during development as shown by scanning electron microscopy of plastic corrosion casts. This provides a new method of viewing fetal lung development that supports the descriptions produced by traditional histological techniques and waxplate reconstructions. This approach, however, has the advantages of allowing examination in three dimensions and of speed and simplicity.

The developmental changes shown in these corrosion casts are largely in agreement with the descriptions of acinar development given by Hislop and Reid. ${ }^{2}$ At 19 weeks' gestation these authors found three generations of airways within the acinus, which they termed respiratory bronchioles. These were lined by both cuboidal epithelium and, in distal parts, flattened epithelium exactly as depicted in figures 3-5.

The period of lung development from the 13th to the 25th week of gestation is called the canalicular period, ${ }^{13}$ which is followed by the terminal sac period that lasts until term. Most observations on the terminal sac period and beyond were made by
Boyden $^{3-7}$ and Reid, ${ }^{2-12}$ who found that the terminal sac period was characterised by the development of "saccules," which are large thin walled airspaces lined by flattened epithelium.

Beyond 28 weeks' gestation Boyden and Reid describe the respiratory acinus as consisting of about three generations of respiratory bronchioles, one or two generations of short, straight, transitional ducts and several generations of saccules. Each saccule is so short that the generations of saccules produced by branching appear as an irregular cluster. Development after 28 weeks' gestation lengthens these structures and also probably increases the number of generations of saccules, the last of which is termed a terminal saccule.

The corrosion cast of the 23 weeks' and 28 weeks' gestation lungs (fig 6) shows "saccules" to be already present. Transitional ducts, however, were not clearly identified until 32 weeks' gestation (fig 8 ), at which age the clustering of saccules is well demonstrated. The decrease in wall thickness - that is, space between the airsacs - takes place continuously throughout development, as noted by previous authors.

The actual size of terminal airspaces has always been a controversial topic because of the different methods favoured both for processing the lung and for calculating the alveolar dimensions.

The first problem is the variable extent to which the alveoli may be expanded by the formalin infusion. A constant pressure for the infusion of formol saline is favoured for adult lungs in an attempt to reproduce the position at the end of inspiration. With this method, however, the size of the alveoli 
will be influenced not only by the infusion pressure but also by the compliance of the alveolar wall. In the fetal lung the amount of interstitial tissue decreases considerably with maturation and so the compliance may increase. Langston and Thurlbeck ${ }^{20}$ have even suggested that compliance increases dramatically as soon as the first breath is taken. Thus the use of a fixed infusion pressure may underinflate the early gestation lung and overinflate the more mature lung. In this study the lungs were inflated to as near as possible the size of the thoracic cavity. The same approach was used by Dunnill' ${ }^{19}$ and Boyden and Tompsett, ' but Davies and Reid ${ }^{21}$ used an infusion pressure of $75 \mathrm{~cm} \mathrm{H}_{2} \mathrm{O}$ and Langston and Thurlbeck ${ }^{2022} 25 \mathrm{~cm}$ of formalin.

The second problem of measuring alveolar diameter in the past was finding or deriving the maximum alveolar dimension from single or serial sections. Dunnill $^{19}$ decided that since few alveoli would be sectioned at their widest point he would multiply the results by an arbitrary factor of $1 \cdot 25$. By this method the alveolar diameter was $150 \mu \mathrm{m}$ at birth, about $230 \mu \mathrm{m}$ at both 4 and 8 years, and $280 \mu \mathrm{m}$ in the adult.

Davies and Reid, ${ }^{21}$ while criticising Dunnill's method, chose to show the increase in alveolar size with age by quoting the number of alveoli per millilitre. Although they achieved their aim, this method does not allow comparison with other data. Boyden and Tompsett ${ }^{7}$ gave a range for alveolar size in a 2 day old infant of $40-120 \mu \mathrm{m}$; while Thurlbeck derived an "alveolar transect distance" in his study of postnatal lung growth, which was $80 \mu \mathrm{m}$ after birth and 90-95 $\mu \mathrm{m}$ at 3-6 years. Langston and Thurlbeck $^{20}$ measured the mean "airspace" in 26 cases-age 19 weeks' gestation to term-and found a wide range of sizes (correlation coefficient = $0 \cdot 67$ ), with a diameter of about $50 \mu \mathrm{m}$ at 19 weeks' gestation and $100 \mu \mathrm{m}$ at term.

Adult alveolar measurements from injection replicas were made by Schreider and Raabe, ${ }^{17}$ who found an average diameter of $250 \mu \mathrm{m}$, and Pump, ${ }^{18}$ who gives an average length of $212 \mu \mathrm{m}$ and width of $205 \mu \mathrm{m}$. Measuring the maximum alveolar dimension is no longer a problem when a three dimensional cast is viewed and large numbers of alveoli can be counted rapidly. The alveolar measurements on the fetal lungs presented in this paper are considerably smaller than those found by Dunnill and more in keeping with those of the other workers mentioned. The values for the adult lung are in close agreement with those of previous workers. The difference between these values and Dunnill's probably results from the problems in defining and identifying the final airspace. Figures 7 and 11 illustrate this problem. Do we regard the terminal airspaces as single large and complex "alveoli" with several protrusions or as several shallow "alveoli" forming a terminal cluster? I have taken the lattter view in agreement with Hansen et al, ${ }^{23}$ who provide a lengthy discussion on this subject.

Whether alveolar size is assessed by serial sections or by corrosion casts, the measurements will be influenced by the extent to which the lung is inflated, any shrinkage that may occur, and, in the case of corrosion casting, whether the infused material penetrates fully into the terminal spaces. Schreider and Raabe $^{17}$ investigated the adult human respiratory acinus by producing silicone rubber casts for two cases. Their casts were made in situ by infusing a set volume of material calculated from physiological data, which aimed to produce a replica representing the airways state at the end of inspiration. They still found, however, that not all alveoli were fully expanded and so had to select the best areas. Since this approach would be impracticable as a routine method for fetal and infant lungs that could be applied to both normal and pathological conditions, I used a different technique. Instead of infusing a precalculated amount of plastic material, I investigated the use of high viscosity resins that would not penetrate into the tissues. Initial attempts with Batson's medium produced a solid mass of lung in many areas resulting from tissue penetration. Tensol Cement No 70 was found to stay strictly within the airspaces and so was used for this study. My method also differs from theirs in that the lungs were fixed in formol saline in an inflated position. Fixing the lungs before casting has the advantage of increasing the number of specimens which can be used and allows the collection of pathological material. It is also particularly useful when a high viscosity plastic is used as it minimises the risk of distortion by casting and makes it easy to recognise the underinfused areas where the plastic ends as a smooth dome without any cell impressions.

The effects of variation in inflation are well illustrated by figure 12 , which shows alveoli in the adult lung. The alveoli in the centre of the picture (group 1) are bulbous structures separated by deep clefts, whereas those on the right of the picture (group 2) are shallow domes. Both are obviously groups of alveoli and both must arise from alveolar sacs (that is, the most terminal airway) since they are blind ends. Thus the shallowness of the group 2 alveoli cannot be explained by their arising from alveolar ducts or respiratory bronchioles, as in figure 13 , and they presumably represent partially inflated alveoli. (This appearance could not result from destructive emphysema, which produces enlarged airspaces by loss of the intervening walls.) Fortunately the partially inflated alveoli in the adult lung (a small per- 
centage of the total) contrast clearly with the fully inflated alveoli. In the fetal lung casts only the most fully inflated acinar structures have been photographed and discussed.

Studies on casts of the adult human lung 1718212324 have concentrated on producing accurate anatomical data relevant to physiological models and the sizes of the adult peripheral airways allow this to be achieved with only a dissecting microscope. This study on fetal lung development has concentrated on the most peripheral airspaces that have the potential for gas exchange and has used the scanning electron microscope to achieve the necessary magnification. As infants can be kept alive in special care baby units at an increasingly early gestational age the maturity of the lung has become the limiting factor in survival. The survival of these infants, with the aid of ventilators, has also produced new pulmonary pathology, such as bronchopulmonary dysplasia. The methods used in this paper will help to provide a new view on such problems and to look again at such subjects as the pulmonary hypoplasia of Potter's syndrome and of congenital diaphragmatic hernia.

I should like to thank Dr WL Landells for providing additional specimens, Mr RF Moss for technical advice, Miss CE Cope for photographic assistance, and Mrs M Coulton for typing the manuscript. Professor Lynne Reid kindly gave permission to reproduce figure 1. Especial thanks are due to Professor PN Dilly for his help and encouragement.

\section{References}

' Bucher U, Reid L. Development of the intrasegmental bronchial tree: the pattern of branching and development of cartilage at various stages of intrauterine life. Thorax 1961;16:207-18.

${ }^{2}$ Hislop A, Reid L. Development of the acinus in the human lung. Thorax 1974;29:90-4.

${ }^{3}$ Boyden EA. The terminal air sacs and their blood supply in a 37 day infant lung. Am J Anat 1965;116:413-28.

${ }^{4}$ Boyden EA. Notes on the development of the lung in infancy and early childhood. $A m$ J Anat 1967;121:749-61.

${ }^{5}$ Boyden EA. The pattern of the terminal air spaces in a premature infant of 30-32 weeks that lived 19 hours. Am J Anat 1969;126:31-40.

${ }^{6}$ Boyden EA. The structure of the pulmonary acinus in a child of six years and eight months. Am J Anat 1971;132:275-99.

${ }^{7}$ Boyden EA, Tompsett DH. The changing patterns in the developing lungs of infants. Acta Anat 1965;61:164 92.

${ }^{8}$ Reid L, Rubino M. The connective tissue septa in the foetal human lung. Thorax 1959;14:3-13.

${ }^{9}$ Elliott FM, Reid L. Some new facts about the pulmonary artery and its branching pattern. Clin Radiol 1965; 16: 193-8.

${ }^{10}$ Hislop A, Reid L. Intrapulmonary arterial development during foetal life-branching pattern and structure. $J$ Anat 1972;113:35-48.

" Hislop A Reid L. Pulmonary arterial development during childhood-branching pattern and structure. Thorax 1973;28:129-35.

${ }^{12}$ Hislop A, Reid L. Fetal and childhood development of the intrapulmonary veins in man-branching pattern and structure. Thorax 1973;28:313-9.

${ }^{13}$ Commission on Embryological Terminology. In: Arey LB, Mossman HW, eds. Nomina embryologica. Leningrad. Bethesda, Maryland: Federation of American Societies for Experimental Biology (FASEB), 1970.

${ }^{14}$ Boyden EA. Development of the human lung. In: Brenneman's Practice of paediatrics. Vol 4. Hagerstown: Harper and Row, 1972:ch 64.

${ }^{15}$ Boyden EA. The structure of compressed lungs in congential diaphragmatic hernia. Am J Anat 1972;134:497-507.

${ }^{16}$ Loosli CG, Potter EL. The prenatal development of the human lung. Anat Rec 1951;109:320-1 (abstract).

17 Schreider JP, Raabe OG. Structure of the human respiratory acinus. Am J Anat 1981;162:221-32.

${ }^{18}$ Pump KK. The morphology of the finer branches of the bronchial tree of the human lung. Dis Chest 1964;46:379-98.

${ }^{19}$ Dunnill MS. Postnatal growth of the lung. Thorax 1962;17:329-33.

${ }^{20}$ Langston C, Thurlbeck WM. Lung growth and development in late gestation and early postnatal life. Perspect Pediatr Pathol 1982; 7:203-35.

${ }^{21}$ Davies G, Reid L. Growth of the alveoli and pulmonary arteries in childhood. Thorax 1970;25:669-81.

${ }^{22}$ Thurlbeck WM. Postnatal human lung growth. Thorax 1982;37:564-71.

${ }^{23}$ Hansen JE, Ampaya EP, Bryant GH, Navin JJ. Branching pattern of airway and airspaces of a single human terminal bronchiole. J Appl Physiol 1975;38:983-9.

${ }^{24}$ Horsfield K, Dart G, Olsen DE, Filley GF, Cumming C Models of the human bronchial tree. J Appl Physiol 1971;31:207-17. 